\title{
SA professor and US engineer transform disabled babies' lives
}

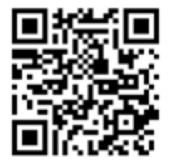

A former Limpopo physiotherapist-turned Professor in Rehabilitation Sciences at the University of Oklahoma has coinvented a mobile device that 'teaches' disabled infants how to crawl, miraculously transforming their cognition, early mobility and life prospects.

Prof. Thubi A Kolobe conceived the idea behind the self-initiated prone-powered crawler (SIPPC), a skate-like device that miraculously enhances the physical abilities of infants, particularly those with cerebral palsy (CP). Many of these children would otherwise never acquire the basic motor skills so fundamental to all future potential learning. The ground-breaking device was displayed at the Smithsonian Innovation Festival at the National Museum of American History in Washington, DC, in September last year, where Kolobe was honoured for her creative thinking. The device teaches infants born with disabilities not just to crawl, but to experience and enjoy independent movement.

\section{Kolobe explains that there is a window of very high synaptic connections in the brain at between 2 and 9 months of age, a critical period for neural development, during which neurologists and paediatricians had previously adopted a 'wait and see' strategy.}

Kolobe became frustrated with the limitations of existing passive therapy, such as gently pulling $\mathrm{CP}$ infants around on or suspending them in a towel (which doesn't reinforce neural pathways). Her research had shown that when babies try to move but do not get the desired effect, their brains prune off that particular motor pathway, leaving them forever disabled. By stratifying five groups of infants and testing them weekly to 6,9 and 12 months, 3 years and 5 years, she was able to track the trajectories of those who ended up with cerebral palsy and those who did not. She discovered that a developmental gap opened up even before term age (birth), becoming dramatic by 3 months of age. Kolobe explains that there is a window of very high synaptic connections in the brain at between 2 and 9 months of age, a critical period for neural development during which neurologists and paediatricians had previously adopted a 'wait and see' strategy. 'My frustration was that the gap was opening up.'

\section{Nudging the infant brain into action}

Although babies generally don't crawl before 9 months, introducing the idea of crawling early enough facilitates brain connections and enhances the child's innate compulsion to move. 'We were waiting until they failed at 9 months,' Kolobe observes. The solution was to intervene early to enable the formation of lasting skills - so she turned to technology.

'I thought there must be a way to support these babies, to bypass those constraints on them and still enable them to drive themselves to move and explore. I wanted something that could harness a baby's early independent movements, to keep them going and convert them into functional use.' So in 2003 she sought out Peter Pidcoe, a former Chicago colleague who runs a 'peculiar' laboratory at Richmond's Virginia Commonwealth University (VCU). People come to him - a physical therapist and engineer - when they need help creating a therapy tool that doesn't yet exist. A 'tinker' of note, Pidcoe fiddles away in a garage in the basement of VCU's West Hospital, constructing devices - from electronic fatigue monitors to predict potential ankle sprains, to prosthetic limbs. Kolobe and her colleagues wrote algorithms incorporated into the electronically powered motorised SIPPC, with sensors that respond to babies' little kicks and weight shifts, rewarding them with an extra boost. The baby lies directly on a cushioned board, secured in place with soft Neoprene straps, and his/her arms and legs connect to sensors attached to computers. Later versions of the SIPPC now have a 'onesie mode', a shirt with embedded sensors to fine-tune directional detection, so that even babies who couldn't generate much force would be reinforced by forward, lateral or backward motion. 'There is sophisticated measurement of the movement of a child's arms and legs, and the SIPPC uses that to identify patterns we

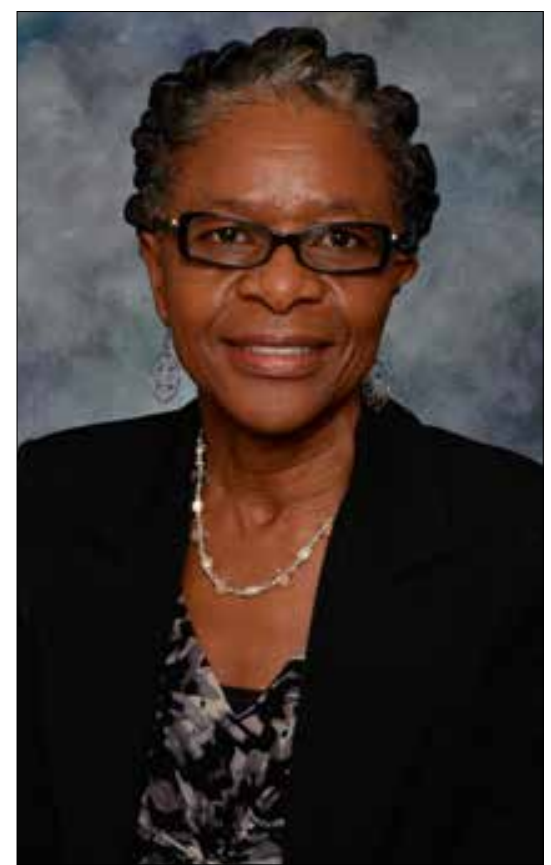

Prof. Thubi Kolobi.

want to reward,' Pidcoe explains. 'You direct the reward to the activities you're trying to achieve.'

\section{An illustrative case}

One of Kolobe's earliest patient successes was Kara Ellis, a twin born at 25 weeks who failed to thrive, living on and off ventilators and eating badly, and whose determined mother, a nurse, came to her for help when her child started making odd movements and scissoring her fingers. Kolobe had by then developed, with colleagues in Chicago, an assessment called the Test of Infant Motor Performance to identify infants most at risk of CP. She had drawn on her research on how brain growth affects motor development in very young children. At just a few months old Kara was diagnosed with cerebral palsy and other motor development delays. Her mother's determination and Internet searching paid off - because with $\mathrm{CP}$ nearly always affecting muscle control and often undiagnosed until the child is a year or more old, it's often too late, the baby already having passed through the stages of learning how to move: rolling, sitting, crawling, cruising and toddling. The random kicks and wriggles of a normal 3-month-old baby do important work by 
forming crucial neural connections that lead to advanced motor skills, such as walking or writing with a pencil. Putting a colourful toy just out of Kara's reach was enough to stimulate her to reach for it - to attempt to lurch in its direction. Kara was rewarded when her effort resulted in movement towards the toy. Eventually, with more and more practice, Kara learnt to quickly move and grab the toy, because her developing brain reinforced the neural connections that control that skill. Tragically, the reverse is also true, with infants' brains having a ruthless 'use it or lose it' policy: if a baby tries to move and doesn't get the desired effect, the brain eventually prunes off that motor pathway.

Monica Ellis said of her daughter: 'Initially she would just lie there on her belly, unmotivated to participate. She sucked her fingers and watched as we tried to entice her to play. To get her moving, we'd pop her fingers out of her mouth, and she'd get mad.' They then got Kara's attention with a toy. The first time she reached for an object on her own, Ellis and Kolobe cheered. 'It flipped a switch, Ellis says. 'She'd turn her head and look at us like "Oh, you like this?" That positive response really helped her to learn to start doing things on her own.'

\section{Kolobe is using a neural feedback net to investigate the real-time activity in babies' brains as they navigate with the SIPPC, while Pidcoe is working to refine the design in the hope that it will be commercially available to parents and therapists at a relatively affordable price.}

With help and reinforcement from the SIPPC, Kara learnt how to crawl. Today, an active 4-year-old in preschool with her sister, Kara walks, talks and runs. She has officially been discharged from physical therapy. Ellis says if it weren't for the SIPPC, the small obstacles of Kara's infancy would have been infinitely more challenging to overcome. 'Even as a little preemie, she let everyone do everything for her because she couldn't do it by herself,' Ellis says. Kolobe, too, is driven to show that even very young infants are highly capable of making huge gains in the face of a potential disability: 'This is what can happen when we harness and multiply the little capabilities that they have so that they can be successful - and

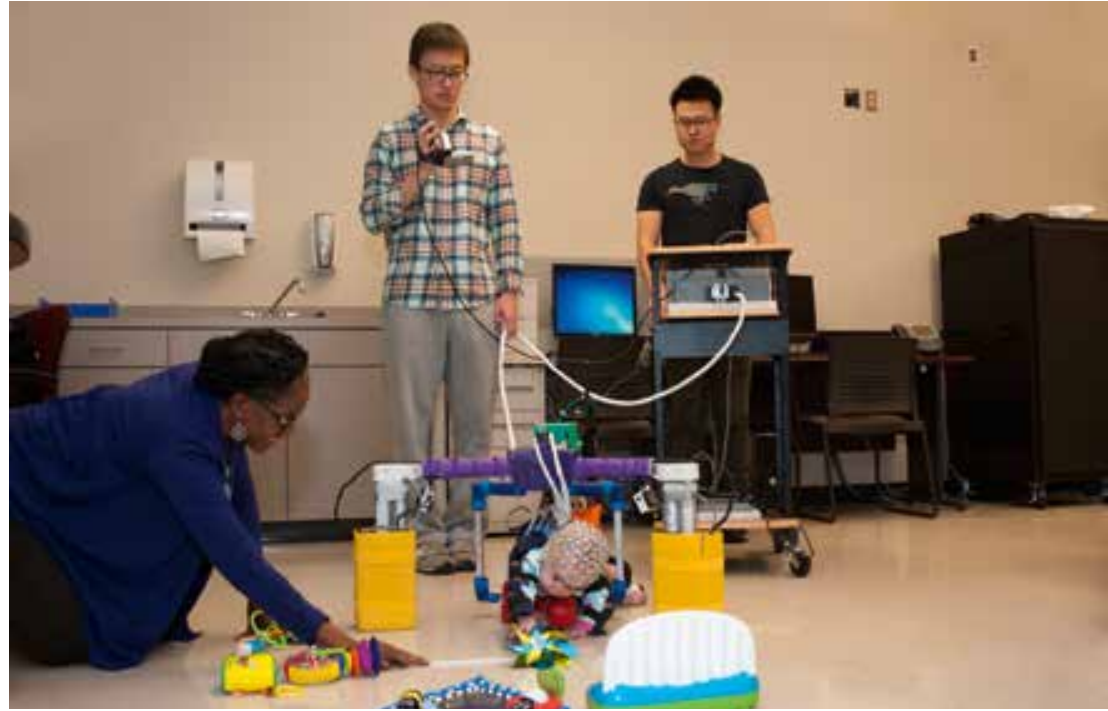

Prof. Thubi Kolobi encourages a baby to crawl using the SIPPC.

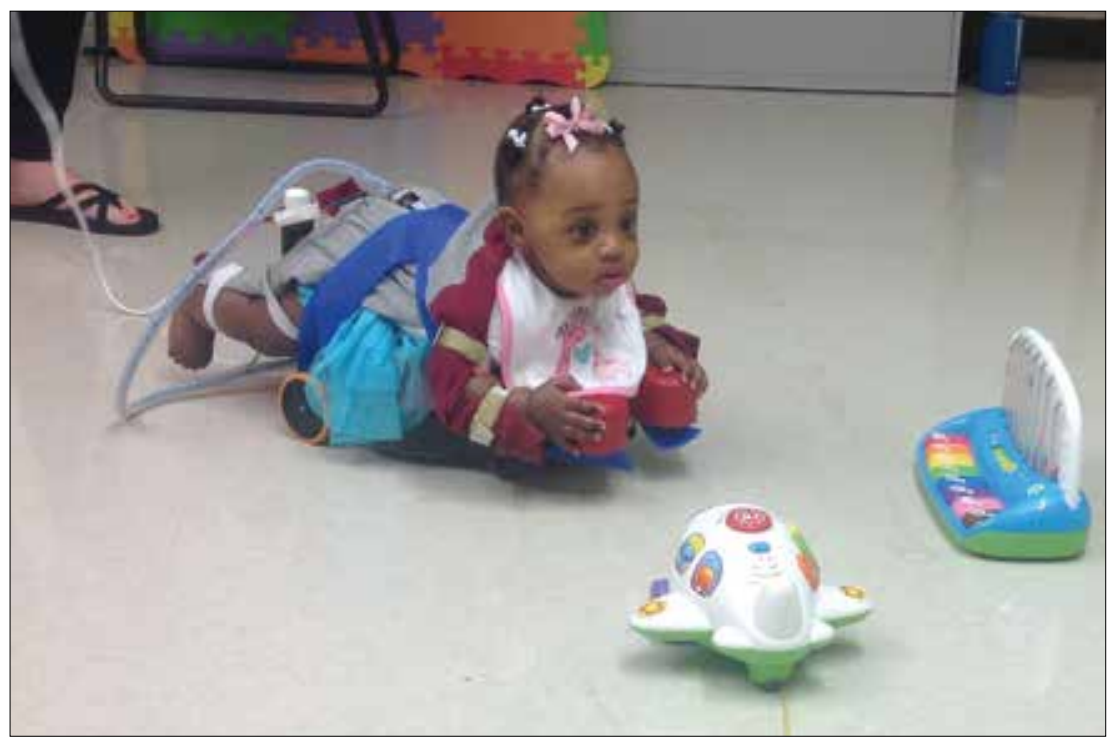

The motorised SIPPC has sensors that respond to a baby's kicks and weight shifts. The device rewards the baby with an extra boost. Photo: University of Oklahoma Health Sciences Center.

only technology can allow us to do that. As a scientist, there are so many questions to be answered, and I feel we haven't even scratched the surface with what we can learn from this.'

\section{'Five years' to public launch}

Kolobe and Pidcoe continue to work on the SIPPC in their respective labs, but in slightly different capacities. Kolobe is using a neural feedback net to investigate the real-time activity in babies' brains as they navigate with the SIPPC, while Pidcoe is working to refine the design in the hope that it will be commercially available to parents and therapists at a relatively affordable price. The versions on display at the Smithsonian Institute currently cost between ZAR3 320 and ZAR5 000 to produce. Ultimately, Kolobe sees versions that can be driven with a cell phone, laptop or iPad-based application. Pidcoe describes the outcome as a classic example of how clinical and engineering tools can blend. Pidcoe and Kolobe patented the SIPPC in January 2015. Although still a prototype, the goal is to miniaturise it, putting all the electronics into a small app, enabling it to be easily stored and transported. Kolobe hopes that within 5 years they will be ready for Federal Drug Administration approval and licensing, with a device that can be used twice a day at home, 5 days a week (currently in use twice a week due to its relatively cumbersome nature). All the infants' movements and distance and direction travelled are coded - and the less they access the 'assist' function, the greater 
the success. A former University of KwaZuluNatal graduate and campus colleague of the late Steve Biko and Mamphele Ramphele in the early 1970s, Kolobe is determined that cost does not become a barrier to access: 'It's important to me that the device cost not more than USD500' (approximately ZAR7 500), she says.

\section{Inventor's empathic journey}

Ironically, a temporary disability of her own set Kolobe off on her unique academic journey. 'In matric I ended up in Baragwanath Hospital after a car crash in which a piece of the steering wheel cost me my voice. The physios would accompany my speech therapist during rounds and I was fascinated ... My brother, a medical technologist at a research institute, took me to see two of them and that was that.' After graduating she was the first and only black physiotherapist at the 1200 -bed Kalafong Hospital - and the only physiotherapist when Attridgeville and Mamelodi erupted in violence in 1976, making travel to the hospital too dangerous for her 11 white colleagues. 'For nearly a month, I did everything, including ICU, out of which came intense reading of foreign journals which ultimately led to my applying for an unprecedented health bursary from the
American Consulate.' Today she basks in the recent observation of a 70-year-old selfmade Oklahoman millionaire, with cerebral palsy himself, while watching an infant use her device. He quipped: 'If I had this when I was small I'd be doing a whole lot better than I am now.'

It seems that countless children's futures stand to be transformed - simply because a passionate therapist refused to give up.

\section{Chris Bateman}

chrisb@hmpg.co.za

S Afr Med J 2016;106(3):229-231.

DOI:10.7196/SAMJ.2016.v106i3.10681 